\title{
Implicit Cultural Templates in Software Design: Renegotiating the Norm with Girl Software
}

\author{
Tiffany Marra, Nichole Pinkard \\ The University of Michigan, School of Education, 610 E. University Room 1228, Ann Arbor, MI 48109 \\ Tel: 734-647-2130 \\ Email: tmarra@umich.edu, pinkard@umich.edu
}

\begin{abstract}
This poster will describe a content analysis of girls' software with the goal of uncovering the implicit epistemological structures within the design of the software. The rubric used to evaluate the software focused on truth, power, identity, voice, and authority.
\end{abstract}

Keywords: gender, elementary school, qualitative assessment

\section{Introduction}

Gender differences in students' use of educational technology has been explained by differences in computer access and software availability, lack of female role models, and the persistence of stereotypical roles of characters in software (AAUW, 1998; Linn, 1985; Giacquinta, Bauer, and Levin, 1993; Turkle, 1988). We hypothesize that in addition to the above explanations, software designers' implicit incorporations of masculine 'cultural templates' (Miraglia, Law, and Collins, 1996; Frissen, 1992) into software inhibits girls from fully engaging with educational technology. We hypothesize that understanding the cultural template embedded in educational software designed for girls and boys will shed light on how designers perpetuate gendered ways of knowing and doing into educational software. The goals for this study is to develop a framework for understanding the cultural template embedded in software that targets upper elementary and middle school girls.

\section{Theoretical Framework}

This study contributes to research in educational technology by applying feminist theory to the study of educational software design. Some researchers have developed assessment rubrics for analyzing educational software design (Reeves, 1997); however, few studies have attempted to explain gender differences in educational technology use through a framework that considers culture as central to design. A key assumption to our approach is that culture is constituted by the learned behaviors that are passed down from generation to generation in a given society. Differing roles for men and women are implicit to all cultural systems. Miraglia, Law, and Collins (1996) identified the notion of cultural "templates" that are continually being redefined and negotiated. They assert that the "power to participate in this process of negotiation has historically been divided along gendered lines."

This research attempts to identify a cultural template within software design and explores how gendered software represents an attempt to renegotiate this template. As Pinkard points out, "when people look at a software package that has a girl on the front, they automatically assume it is made for girls, but when there is a boy on the front it is assumed to be gender neutral (1999)." Seeing a boy on a software package has become the accepted cultural template for software, whereas seeing a girl on the cover is interpreted as differing from the norm and is identified as targeting a specific population. As Frissen states, technology has favored masculine practices and has ignored how feminine practices would utilize technology in different ways (Frissen, 1992; Wajcman, 1991). By diverging from the cultural template and producing "girl" software, designers have tried to target feminine practices. In doing so, designers have made assumptions about which activities represent feminine practices and values. This study attempts to outline the assumptions that have been incorporated into "girl" software, and explores the implications of those assumptions and design decisions.

\section{Methods}

For this study, 5 pieces of top-selling girls software, American Girls' Premiere, Let's Talk About Me!, Secret Paths to the Sea, Laura's Happy Adventures, and Nancy Drew's Secrets Can Kill, were critically examined for the epistemological structures being promoted in the software. The rubric used to evaluate the software tried to 
make explicit structures of truth, power, identity, voice, and authority within the software. After extensive use of each piece of software, they were analyzed using the rubric.

\section{Preliminary Findings}

What the software analysis uncovered was that through the software, girls are encouraged to be passive users of the software. The user is unable to express her voice and the software reflects one truth that is not defined by the user. In addition, the female role models in the software were disempowered and the authority figures in the software are not easy to relate to for girl users. In most cases the authority figure is represented as either a disembodied object and/or as men. Unlike with most uses of technology, girls are not given the opportunity to perform tasks that they normally could not do without the software. The activities within the girls' software are achievable in real-life.

\section{References}

American Association of University Women (1998). Gender Gaps: Where Schools Will Fail Our Children. Washington, DC.

Frissen, V. (1992). Trapped in electronic cages? Gender and new information technologies in the public and private domain: an overview of research. Media, Culture, and Society, 14(1), 31-49.

Giacquinta, J.B, Bauer, J.A. and Levin, J.E. (1993). Beyond Technology's Promise. Cambridge, England: Cambridge University Press.

Linn, M.C. (1985). Fostering Equitable Consequences From Computer Learning Environments. Sex Roles, 13, 229240.

Miraglia, E., Law, R., and Collins, P. (1996). What is Culture? [Essay Online]. March 1, 1996. [cited November 13, 1999]. Available from world wide web at http://www.wsu.edu:8001/vcwsu/commons/topics/culture/culture-index.html

Pinkard, N. (1999). Personal Communication on November 1, 1999.

Pinkard, N. \& Marra, T (in preparation). Examining Gender \& Technology: A formative study of students' computer interests, self-image, and software preferences.

Reeves, T. (1997). Evaluating What Really Matters in Computer-Based Education. [Paper Online]. November 21, 1997. [cited November 5, 1999]. Available from the world wide web at http://www.educationau.edu.au/archives/cp/reeves.htm

Turkle, S. (1988). Computational Reticence: Why women fear the intimate machine. In C. Kramarae (Ed.), Technology and Women's Voices. New York: Routledge and Kegan Paul.

Wajcman, J. (1991). Feminism Confronts Technology. University Park, PA: The Pennsylvania State University Press.

\section{Acknowledgment}

The authors would like to thank the Institute for Research on Women and Gender and the Children's Software Revue for providing support for this project. 